\title{
Rehabilitation of RC buildings from the late 19th - early 20th centuries - methodological discussion
}

\author{
E. Paupério \\ University of Porto - Construction Institute, Porto, Portugal \\ X. Romão \\ University of Porto - Faculty of Engineering, Porto, Portugal
}

Reinforced concrete (RC) constructions from the late 19th - early 20th centuries present new challenges associated to their conservation and repair. The specificities involved in the conservation/rehabilitation of historical and heritage RC constructions require a special approach that must account for several restrictions. Such restrictions are related to the safeguarding of the heritage's cultural value, significance and authenticity that have to be weighed against safety and durability requirements, as well as against duration and budget constraints of the intervention. For the case of late 19th - early 20th centuries RC constructions, such issues are more complex since materials have evolved and construction techniques of that era cannot be replicated. Some issues that are raised when dealing with the conservation/rehabilitation of these constructions are addressed herein based on a case study. A methodological approach for the conservation of these constructions is discussed, highlighting challenges that need to be addressed.

\section{INTRODUCTION}

The main objective of the proposed paper is to create awareness about the challenges involved in the conservation and rehabilitation of historical reinforced concrete (RC) constructions from the late 19th and early 20th centuries. By analyzing specific aspects related to the identification, conservation and protection of this type heritage constructions, methodological challenges are highlighted regarding the definition of interventions aiming to preserve these constructions. The importance of these historical RC constructions is tightly connected to the several social, technological and cultural changes that occurred in the late 19th and early 20th centuries. These changes, which are connected to industrialization, to the new materials and construction techniques being developed and the new functions of the constructions, led to a profound evolution of architecture, urban planning and construction to meet the needs of modern society. Therefore, the historical and heritage RC constructions of this era include a large number of constructions with variable characteristics that reflect both modern and traditional values. The lack of interest in preserving these constructions may lead to irreparable losses, namely by depriving future generations of the constructions from this period. It is therefore vital to develop strategies to identify, study and protect these constructions, as well as to develop public awareness about their importance, a fact highlighted by the significant number of public constructions with an important social value that were built during this period (Larena et al 2011).

Given the need to protect the historical and heritage RC constructions from this period, their conservation and rehabilitation can be seen to present new challenges. Natural deterioration caused by the ageing of the materials and their exposure to severe environmental conditions had led to a significant increase of the vulnerability of such constructions. Given the specificities of older RC constructions, a special conservation approach is required. Furthermore, when facing the need to make conservation interventions to preserve or restore degraded heritage constructions, there are a number of restrictions that must also be dealt with. Such restrictions are related to the safeguarding of the heritage's cultural value, significance and authenticity that have to be weighed against structural safety and durability requirements, as well as against duration and budget constraints of the intervention. For the case of RC constructions from the late 19th - early 20th centuries, such issues are increasingly more complex since materials have evolved and RC construction techniques of that era cannot be replicated.

In this context, important issues frequently raised when dealing with the conservation/rehabilitation of historical and heritage RC constructions from this period are addressed herein. Based on a case study, a methodological approach is then discussed and some of the challenges that need to be addressed in the conservation of these constructions are highlighted. 
2 REVISING CONSERVATION PRINCIPLES FOR LATE 19TH - EARLY 20TH CENTURY RC CONSTRUCTIONS

The principles of the Venice Charter and the critical restoration theory of Cesare Brandi are the main documents based on which most of the existing international charters and principles were developed (Kalman 2014). Baseline principles such as the need to obtain knowledge about the object under analysis, the minimal intervention or the preventive maintenance are universally accepted and generally applied to interventions. By analyzing these international charters and principles regarding the rehabilitation of the structural elements of a construction, these documents clearly express the importance of obtaining reliable scientific knowledge about these elements. Furthermore, references to the historical importance and value of the structure of a construction are also present.

When analyzing late 19th - early 20th century constructions, their characteristics are seen to be not only connected to the development of new materials (iron, steel and concrete) and new building technologies, but also to the social concerns and comfort needs that also started to emerge at that time. Therefore, it is important to define conservation objectives and cultural significance values for these constructions that reflect their social functions as well as their technological advancements. Among other aspects, such objectives and values need to account for the fact that:

- These constructions possess an experimentalist and innovative nature resulting from the use of different proprietary systems of RC construction (e.g. Hennebique, Coignet, Considère, Monier, etc) and from the large variability of construction processes used at that time. As such, many different types of design and construction practices can be found for the same building typology;

- The material characteristics (e.g. the type of cement and steel) and construction practices are now quite different from those used in early RC constructions;

- The theoretical calculation/design models and construction processes of RC constructions evolved throughout the 20th century due to the development and constant updating of technical standards and norms.

In light of these arguments, the concepts of "traditional knowledge" or "traditional construction practice" that are often associated to materials and construction techniques that can be replicated are not applicable to RC construction. Therefore, concepts such as authenticity, reversibility or patina valuation usually referred by international charters and principles (Zancheti et al 2006) need to be revised since they are not suitable for RC constructions. Since the original materials and building techniques of these constructions can't be replicated, addressing the issue of authenticity in conservation operations could be done by preserving the intent of the original design. This could then be achieved by maintaining its form, functionality and social meaning (if it exists). With respect to valuing the patina in these constructions, it is believed there is little sense in addressing this concept since the ageing process of recent RC constructions is not part of our collective memory. Furthermore, in these constructions, patina is, in most cases, found to be an indicator of inadequate material performance.

According to Monteros (2011), conservation theory should now focus on the definition of guidelines to establish identification, protection and intervention criteria for historical and heritage constructions from the late 19th and 20th centuries. In this context, reference is made to the Recommendation No. R (91) 13 from the Committee of Ministers of the Council of Europe. This pioneering document points out several factors that should be taken into account in the preservation of the architectural heritage of the 20th century. Furthermore, based on recent rehabilitation experiences, Moreira (2011) expresses some of the challenges the conservation and rehabilitation practice of these constructions faces and that are related with:

- Overcoming the fact that restoring the functionality for which a given construction was originally designed is sometimes impossible since it may now be obsolete;

- The fact that traditional construction techniques do not exist for these constructions;

- Material compatibility issues;

- The replacement and maintenance of the construction services systems (i.e. electrical systems, plumbing, heating);

- The need to implement regular preventive maintenance operations;

- The difficulty in establishing classification or protection principles/criteria for heritage constructions from the late 19th and 20th centuries.

With respect to this last factor, Zancheti (2014) highlights the need to include criteria related to the economic value, the functional value and the affective value when analyzing the protection and preservation of these constructions.

In addition to these aspects, ensuring the structural safety of these constructions for their preservation is also a challenge due to the characteristics of the structural elements usually found. The structure of these constructions often involves elements with slender cross sections covering large spans. This factor together with the previously referred construction variability, the difficulties in understanding the real structural behavior and in obtaining reliable data on what was actually built, and the inability to quantify the effects of material ageing and degradation create a series of obstacles to validate structural safety ac- 
cording to current standards. Therefore, it is believed that the structural engineering field should be actively involved in the development of a conservation theory for these constructions since structural safety principles and the durability of the rehabilitation solutions will govern the preservation of these constructions.

In order to further address this last issue, a case studies is presented in the following where challenges for the rehabilitation of a RC construction are addressed with more detail from the point of view of the structural engineering requirements.

\section{SELECTED CASE STUDY: THE BOLHÃO MARKET}

\subsection{General description of the building}

The Bolhão Market was built between 1914 and 1917 in Porto, Portugal, and was listed as a construction of Public Interest in 2013. The building is currently severely degraded even though it maintains its original function as the main market of fresh produce in the city. The building is located in a city block limited by the four streets in the downtown area of Porto (Fig. 1). The layout of the building was adapted to the local topography of the site which has a rise of $6.0 \mathrm{~m}$ between the north side and south side streets. Given this slope, the building height at the south side entrance is close to $15.0 \mathrm{~m}$ (Fig. 2) which is about twice the height of the building at the north side. This means the building has two stories that accommodate the referred slope in order to provide two main ground level accesses: one from the south side to the $1^{\text {st }}$ story and another from the north side to the $2^{\text {nd }}$ story gallery.

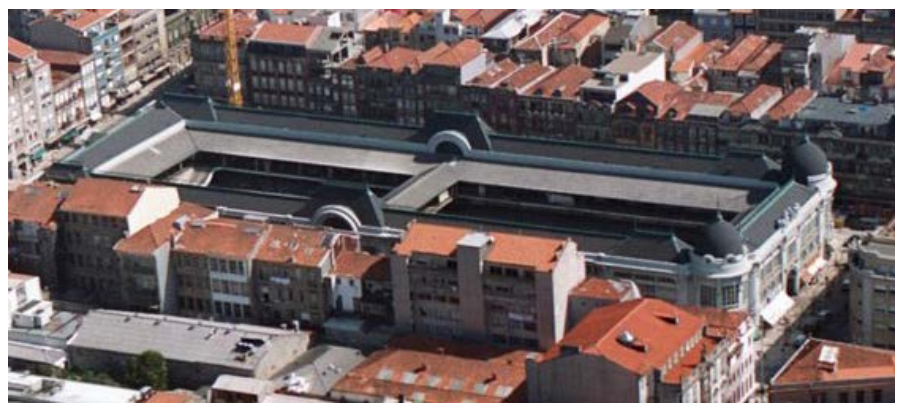

Figure 1. Aerial view of the Bolhão Market.

The vertical structure of the building is mostly made of granite masonry walls complemented with cast iron columns supporting the gallery and RC columns in some internal areas. On the other hand, the horizontal structure of the $2^{\text {nd }}$ story is entirely made of RC beams and slabs, while the roof structure is made of timber trusses.

A structural survey of the Bolhão Market was recently carried out as part of a rehabilitation project being developed for the building. Since design and construction documents about the buildings were not found (a common situation in RC constructions of this era) and it was necessary to perform a structural safety assessment due to the existing structural damage in parts of the building, having a detailed survey was essential. A survey of the building geometry, materials and level of existing structural damage was then carried out by the Construction Institute of the Faculty of Engineering of the University of Porto (Costa et al 2009). Since the current analysis is related to the rehabilitation of RC elements, only issues related to the beams and slabs of the RC $2^{\text {nd }}$ story structure are addressed in the following for the sake of brevity. Furthermore, it is noted that, based on the information obtained from the survey, those were the elements leading to greater structural safety concerns.

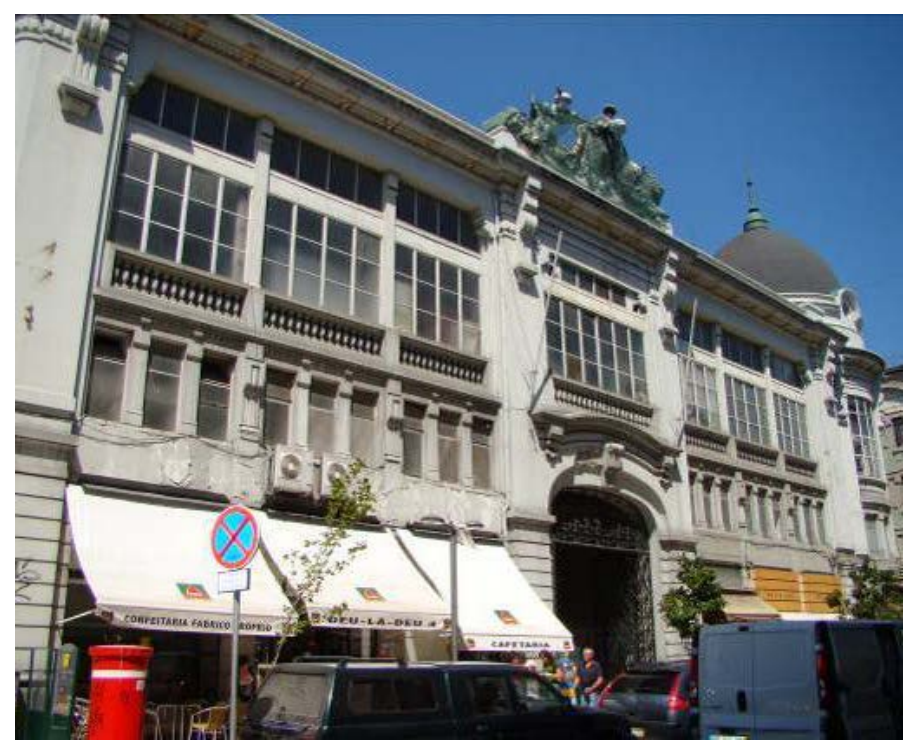

Figure 2. South side entrance of the Bolhão Market.

\subsection{Survey of the conservation state of the building}

As previously referred, the $2^{\text {nd }}$ story structure is made of RC beams and slabs. The beams are arranged orthogonally and define a structural grid of main and secondary beams setting the boundaries of the slab panels. The main beams (that have a larger cross section) overcome the transversal span of the gallery (about $5.0 \mathrm{~m}$ ) while the secondary beams are supported by the main ones (Fig. 3). Some beams were seen to have a composite cross section with an I-shaped steel profile embedded in the concrete. The slab panels of the story are $2.0 \times 3.0 \mathrm{~m}^{2}$ except the peripheral panels which are $2.0 \times 2.0 \mathrm{~m}^{2}$ (Fig. 3), but all the panels are made of solid slabs with a structural thickness of $0.10 \mathrm{~m}$. Although the structural thickness of the slabs was considered to be $0.10 \mathrm{~m}$, an additional $0.10 \mathrm{~m}$ thick layer of concrete was also found on top of the structural thickness. This additional layer was made with a different type of concrete but its contribution to the overall mechanical behavior and stiffness of the slabs was found to be significant. 

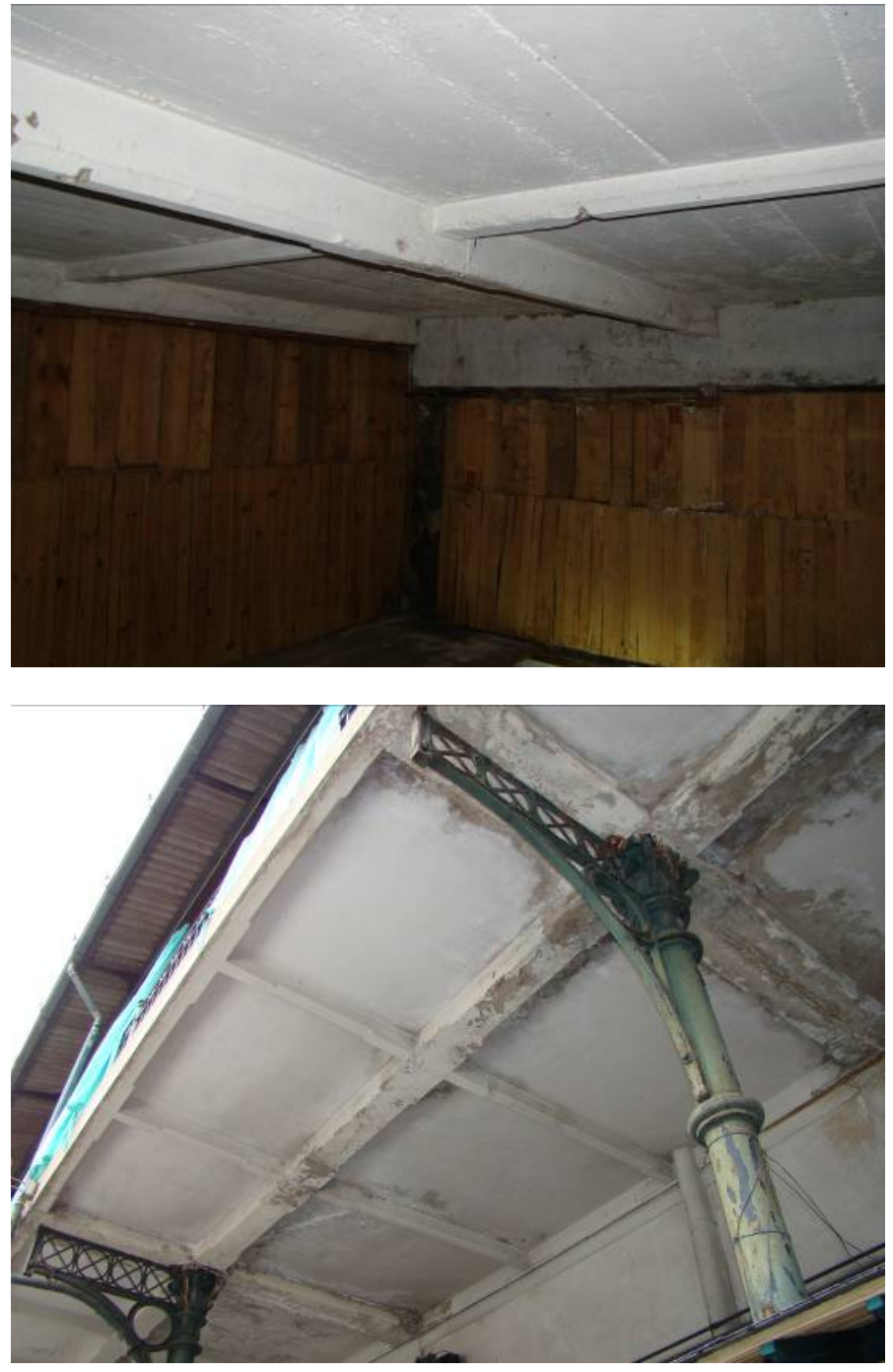

Figure 3 . View of the RC beams and slabs of the $2^{\text {nd }}$ story structure of the Bolhão Market.

Based on the survey that was carried out, these structural elements were found to be in a reasonable state of conservation since they were still able to maintain their structural function. Nevertheless, several beams exhibited concrete spalling and reinforcement corrosion. In some of these beams, the embedded steel profile was already visible and showed obvious signs of corrosion while the steel reinforcement bars also exhibited a reduction of their cross section (Fig. 4). Furthermore, in some areas of the $2^{\text {nd }}$ story gallery floor, the RC structure exhibited visible levels of vertical deformation and relative displacements (Fig. 5). After carrying out a geotechnical analysis, this damage was found to be related to the occurrence of differential settlements of the foundations since part of the building was constructed over a landfill with a height close to $15.0 \mathrm{~m}$ (Costa et al 2009). Due to the referred corrosion of some of the RC elements and to the deformations in some parts of the gallery, several areas of the gallery were shored as a precautionary measure (Fig. 5).

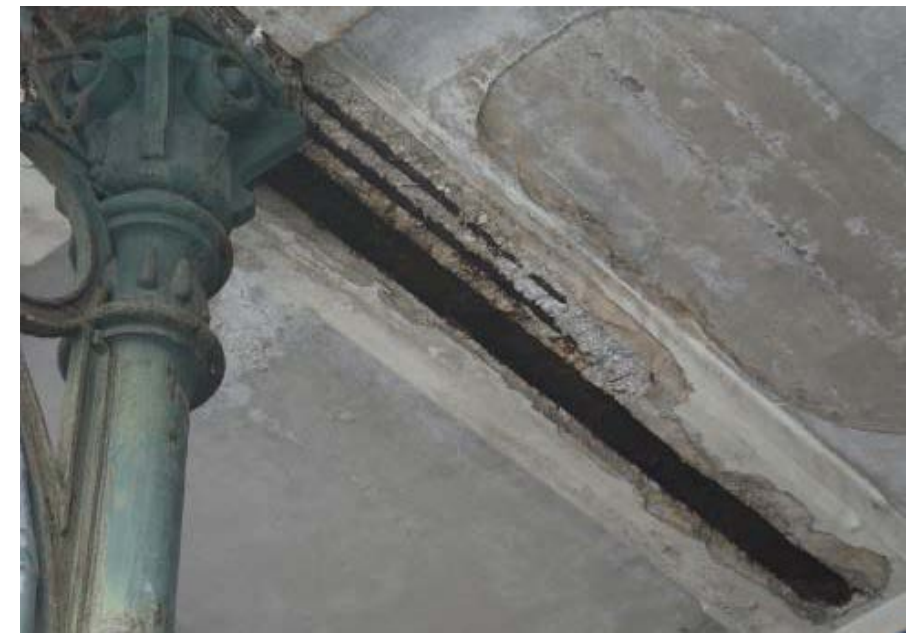

Figure 4. View of the corroded steel profile and reinforcement bars of the beams of the $2^{\text {nd }}$ story structure.

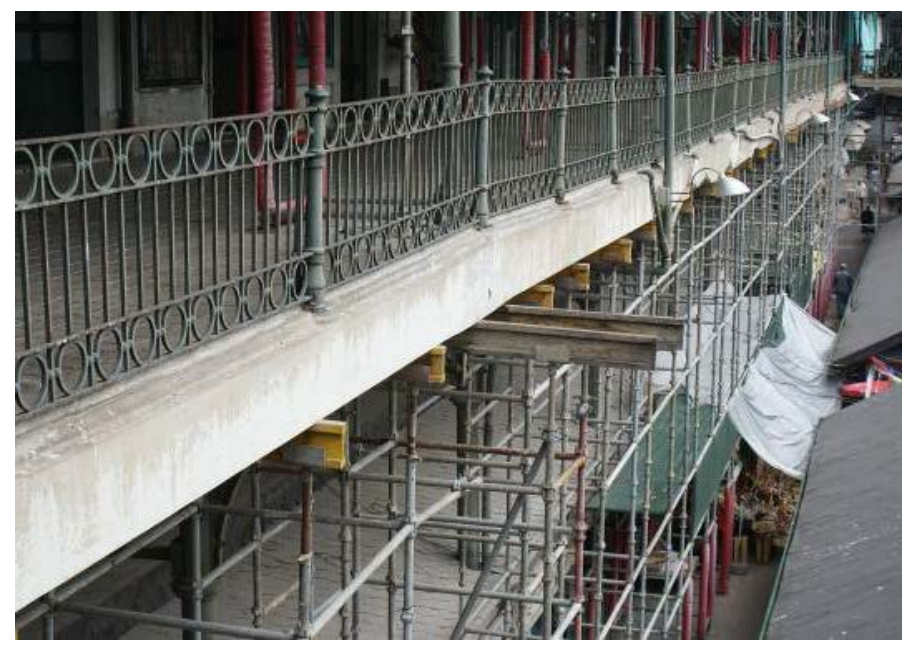

Figure 5. View of the vertical deformations and the shoring of the $2^{\text {nd }}$ story gallery floor.

In addition to the geometrical survey of the elements, the position, depth and bar size of concrete reinforcement was also analyzed by visual inspection in elements exhibiting concrete spalling and also using electronic rebar detectors. The data obtained using the electronic rebar detectors was validated in some cases by chipping the concrete cover layer in some elements. Based on this survey, comprehensive information was able to be obtained regarding the beam and slab reinforcement details. The longitudinal reinforcement of all the elements was found to be made of smooth rebars. The bottom reinforcement of the majority of the slabs was seen to be a $0.10 \times$ $0.10 \mathrm{~m}^{2}$ grid of $3 / 16$ ', rebars and no top reinforcement was found in these elements. The survey led to the identification of 36 different types of beams. All beams were seen to have matching top and bottom reinforcements that run continuously across the span. The diameter of the beam stirrups was seen to be $1 / 8$ '" in several elements and was assumed to be the same across all the beams. Table 1 illustrates the reinforcement details of three beams of the $2^{\text {nd }}$ story structure. 
With respect to the characterization of the concrete strength, since results from previous concrete compression tests carried out in cores extracted from the building were available (Luxan et al 1997), additional cores were not extracted to avoid causing further damage to the structure. Therefore, only nondestructive tests were carried out with a rebound hammer to analyze the variability of the concrete quality and to partially validate the expected concrete strength. Carbonation measurements were also carried out in RC elements and carbonation depth was found to be lower than $1 \mathrm{~cm}$.

Table 1. Reinforcement details found in three beams.

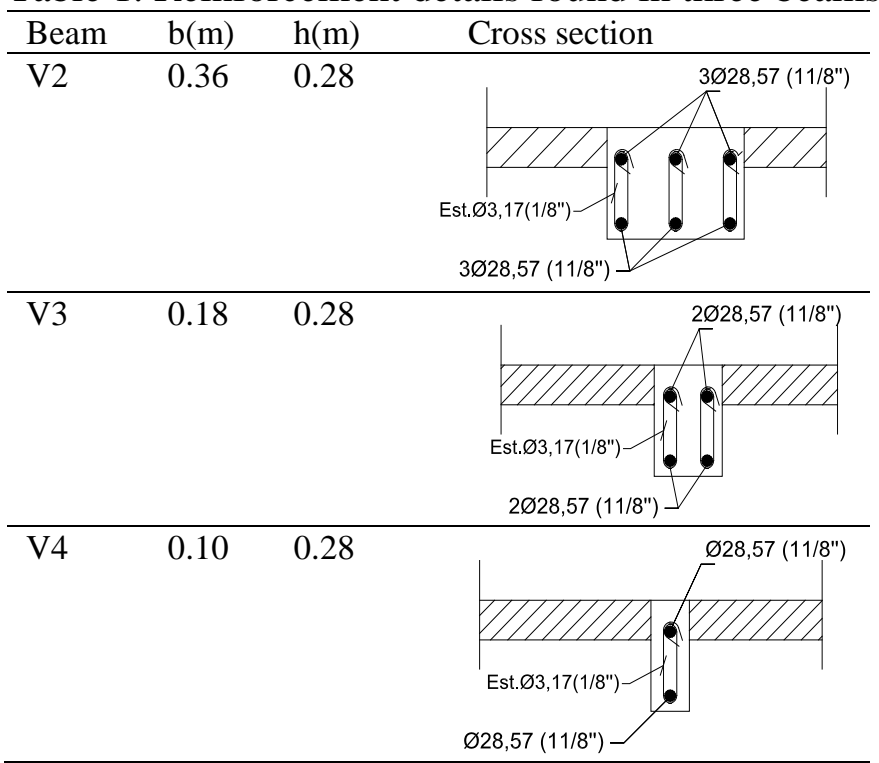

\subsection{Issues and challenges regarding the structural safety assessment}

When dealing with the structural safety assessment of older RC structures such as those from the late 19th - early 20th century, one of the difficulties lies in the ability to represent their complex structural behavior as realistically as possible. This difficulty is often amplified by the fact that part of the data available to carry out the assessment is limited and/or uncertain. Structural surveys and technical inspections of course play a fundamental role in this assessment since the necessary critical information can be obtained from those procedures. However, time and budget restrictions, as well as the need to carry out a limited amount of destructive survey operations, may bound the effectiveness of these procedures and the reliability of the data that is obtained. As such, the need to quantify the level of structural safety is often a challenge requiring the use of structurespecific procedures.

As previously mentioned, structural safety concerns in the Bolhão Market were mostly felt regarding the $2^{\text {nd }}$ story RC structure, given its level of damage and degradation. A first step towards evaluating its structural safety consisted in analyzing the behavior of one slab panel assuming conservative hypotheses in terms of the slab's effective structural thickness, support and boundary conditions (i.e. the slab was assumed to be a $0.10 \mathrm{~m}$ thick one-way slab supported by the main beams and no continuity was considered between adjacent slab panels). Although this preliminary analysis suggested the slab panel was grossly unsafe, the lack of visible signs of flexural damage in the slabs emphasized the over conservativeness of this outcome. Therefore, this result was believed to be too unrealistic and analyzing the true behavior and safety level of the floor structure was found to require a more comprehensive modelling approach. This approach would need to be able to capture the true load transfer mechanisms of the structure as well as the interaction between the grid of beams and the slab panels. A joint behavior of these elements is expected since the main beams only have a depth of $0.18 \mathrm{~m}$ below the slab and, therefore, are not seen to have enough stiffness to provide support for the slab. Furthermore, given the absence of top reinforcement in the slabs, this alleged support provided by the main beams would have led to deformations and damage along that area. The fact that such deformations and damages were not found in situ corroborated the idea of a joint behavior involving the grid of beams and the slab panels.

A detailed numerical model of the floor structure was then developed to capture the joint behavior of the grid of beams and the slab panels. Nevertheless, several aspects of the model having a significant impact on the structural safety assessment results remained uncertain: How much of the slab's additional layer of concrete with different characteristics contributes to the stiffness and strength of the slab? What is the true mechanical behavior of the materials given their damage, level of cracking and agerelated degradation? How much of the floor's true behavior is affected by the existing vertical deformations and relative displacements?

Despite the importance of these uncertain factors, the detailed numerical model was able to provide a more realistic representation of the structural behavior. Furthermore, after several structural safety assessments based on that modelling approach and using different possible scenarios of the uncertain factors, a possible range of the structure's maximum admissible vertical load was obtained. Nevertheless, in spite of the valuable data obtained from this numeral approach, the results were not able to provide an objective measure of the available margin of safety. Therefore, a series of load tests in part of the RC $2^{\text {nd }}$ story structure were then carried out up to a certain target level of loading in order to assess the strength of the structure and its corresponding vertical deflection.

The load tests were carried in three different areas of the $2^{\text {nd }}$ story gallery floor (sites A, B and C in Fig. 6 ) and their main objective was to assess the struc- 
tural behavior under stepwise increasing distributed static loads. The load was increased up to levels between 2 to 3 times the live load value established by the current Portuguese standard (i.e. $4 \mathrm{kN} / \mathrm{m}^{2}$ ). The floors were loaded using interconnected water reservoirs that were gradually filled and the load levels were measured using a flow meter (Figs. 7 and 8). The floor deflections were measured using LVDT transducers and potentiometer-type displacement transducers placed below the floors and beams or above them, depending on access restrictions. The loading was applied in steps of $100 \mathrm{~kg} / \mathrm{m}^{2}$ while the unloading steps were $150 \mathrm{~kg} / \mathrm{m}^{2}$. Each load step was only applied after the stabilization of the transducer readings from the previous step. According to the structural measurements that were obtained, the structural behavior of the floors was found to be mostly linear elastic and the vertical deflection levels were very low (e.g. for a load level of $1100 \mathrm{~kg} / \mathrm{m}^{2}$, an average deflection of about $0.7 \mathrm{~mm}$ was obtained). Based on the load test results, the RC structure of the $2^{\text {nd }}$ story was found to exhibit adequate levels of structural safety according to the load levels that are established by current standards.

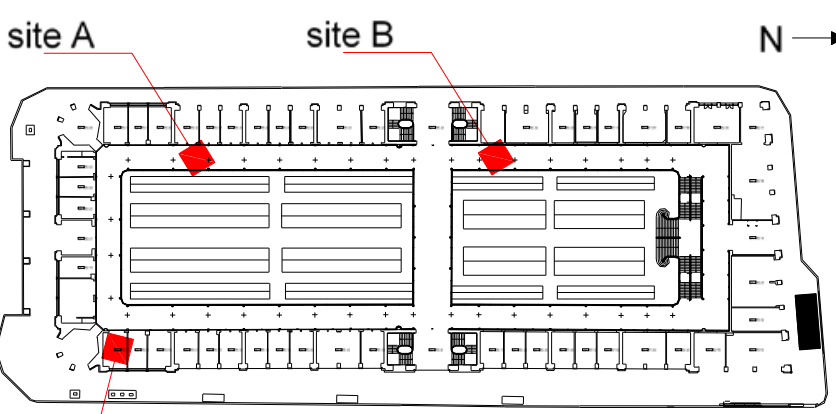

site C

Figure 6 . Location of the load tests carried out in the $2^{\text {nd }}$ story gallery floor.

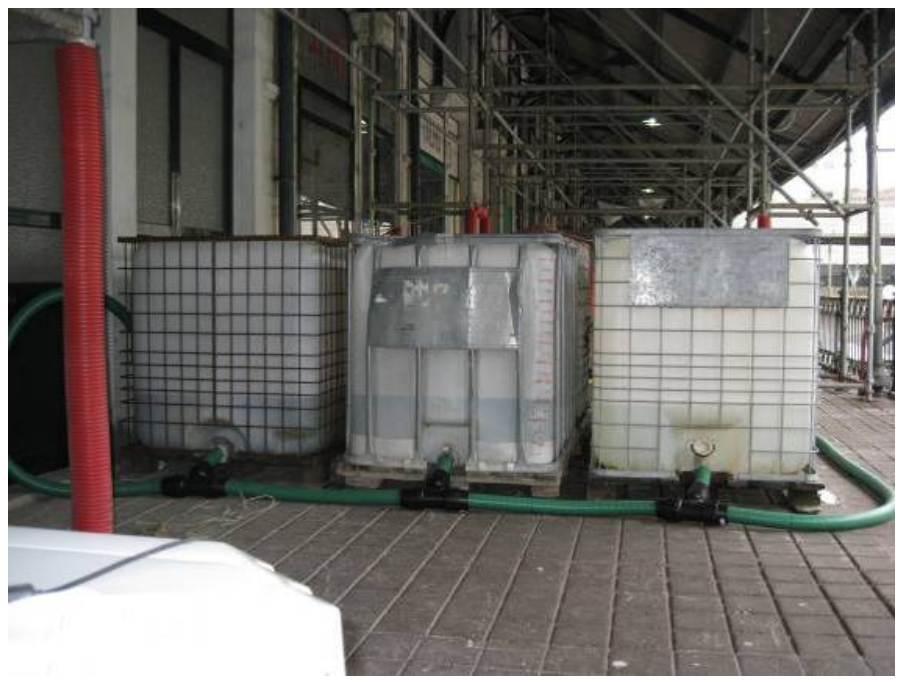

Figure 7. View of the water reservoirs used for the loading for the load tests at site A.

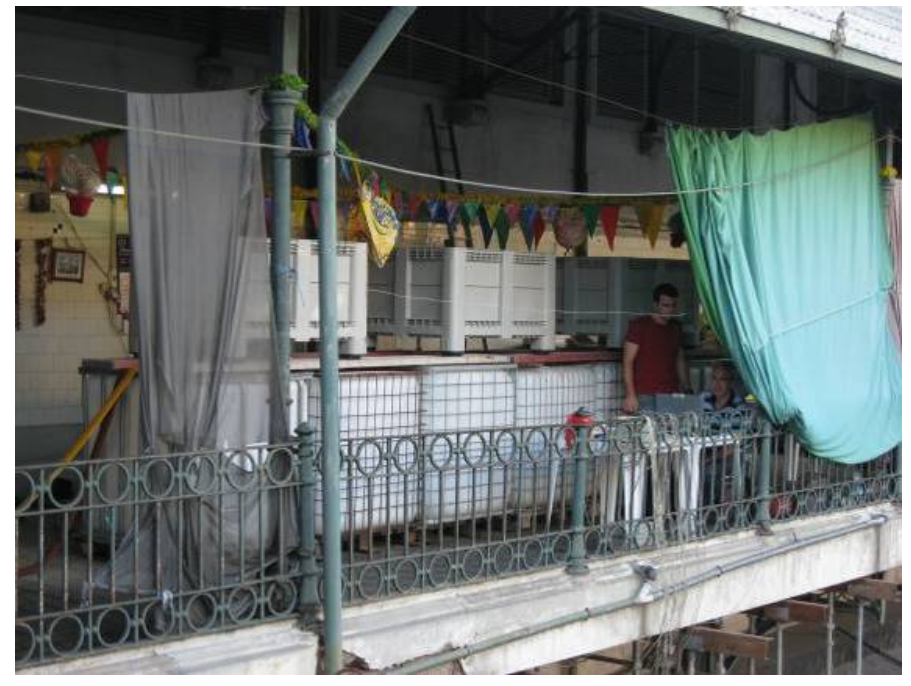

Figure 8. View of the water reservoirs used for the loading for the load tests at site $B$.

\section{METHODOLOGICAL REMARKS FOR THE REHABILITATION OF HISTORICAL RC CONSTRUCTIONS}

One of the challenges in the conservation of late $19^{\text {th }}$ - early $20^{\text {th }}$ century historical RC constructions is to ensure their structural safety without involving rehabilitation approaches that will deface them. Since the structure of these constructions was not designed according to the modern safety requirements established by current standards, and since their structural elements are often seen to have small cross section sizes, the structural safety of these constructions is entirely controlled by the adequate performance of $\mathrm{RC}$ as a structural material. Therefore, defining an efficient rehabilitation approach for these constructions requires reliable information regarding what was actually built. Since historical records containing this information are often non-existent, the survey of the geometry, materials and level of existing structural damage of the construction is a vital operation, as noted in several international documents (e.g. see ICOMOS 2000, ISCARSAH 2003). The scientific knowledge obtained from such surveys will then enable "reconstructing" the original structural design solution which is fundamental for the structural safety assessment process.

Without accurate information regarding the geometric, mechanical and material characteristics of the construction, structural safety can't be analysed according to modem approaches. As such, both the structural safety assessment and the conservation approach that is selected will inevitably need to be more conservative and may lead to more intrusive rehabilitation solutions from the structural engineering point of view. In particular, these intrusive solutions will probably involve increasing the size of the elements' cross section (e.g. due to the need to strengthen some elements) which will ultimately alter the architectural form of the construction. Such 
modifications are particularly important in RC constructions of this era since, as referred before, maintaining their overall image, architectural forms and proportions is an important aspect of preserving their authenticity.

The importance of the referred survey operations is undeniable and, in theory, they should be able to provide the necessary technical and scientific information about the construction under analysis. However, in some cases, such in-depth level of knowledge is not able to be obtained unless more destructive probing operations and tests are carried out. In these cases, a minimum destruction principle should be enforced in order to find a balance between the amount and importance of the information that can be obtained by a certain destructive operation and the level of damage that such operation will cause to the construction. Ultimately, one should not forget that damaging the construction to obtain information contradicts the purpose of preserving the construction.

In cases where obtaining the full length of the necessary information about a given construction from survey operations will cause too much damage to the construction, modelling the behaviour of the construction realistically to analyse its structural safety may not be possible. In such cases, alternative approaches need to be established to analyse structural safety. Such alternatives are sometimes also needed in situations where the survey operations provides the necessary information but the complexity of the structural behaviour is not able to be fully captured by a numerical model. This situation can occur when the model is unable to represent the existing damage of the construction, the age-related material degradation effects or the influence of existing deformations. In such situations, the structural safety assessment may require the use of in situ load tests. Alternatively, if load tests are unable to be carried out, data obtained from medium-to-long term structural monitoring systems can also be used to support a structural safety analysis.

Since the rehabilitation of these constructions is unable to be carried out using original materials or building techniques, mechanical and chemical compatibility issues between old and new materials must be accounted for when defining such interventions. For example, after its start, reinforcement corrosion is very difficult to stop and the applicability of corrosion inhibitors is still unclear, both in terms of their advantages in reducing the progression of corrosion (Bertolini et al 2011) and potential chemical compatibility issues. Moreover, the durability of any intervention must not be overlooked and the durability requirements need to be inevitably associated with cost and budget constraints, with the time needed to carry out the intervention and with the existence of a preventive maintenance programme.
Still, discussing the conservation of late $19^{\text {th }}$ - early $20^{\text {th }}$ century historical RC constructions must not be limited to issues related to the structural safety and the mechanical behaviour of these constructions. New conservation concepts need also to be involved and adapted to this new type of heritage. As referred before, classical conservation principles need to be revised for these constructions and new identification, protection and intervention criteria are also required. As discussed, preserving the original materials and construction processes or valuing the patina are inadequate concepts in this context. Preserving the authenticity of these constructions is more about maintaining the architectural form and the social functions that are associated to the technological advancements of that time. Therefore, in addition to the aesthetic and historical values, the economic value, the functional value and the affective value (Zancheti 2014) should also be taken into account in the protection and preservation of these constructions. Nevertheless, the conservation and rehabilitation practice of late $19^{\text {th }}$ - early $20^{\text {th }}$ century historical RC constructions must not forget to answer these additional questions when defining an intervention: What for? How long should it last? and Under what conditions?

\section{REFERENCES}

Costa, A., Arêde, A., Paupério, E., Castro, J., Guedes, J., Lopes, V., Dias, T., Neves, F., Coutinho, D., Milheiro, J., Monteiro, A. \& Costa, A., 2009. Bolhão Market building. Inspection and structural diagnosis report. Instituto da Construção da Faculdade de Engenharia da Universidade do Porto. (in Portuguese)

Bertolini, L., Carsana, M., Gastaldi, M., Lollini, F. \& Redaelli, E., 2011. Corrosion assessment and restoration strategies of reinforced concrete buildings of the cultural heritage. Materials and corrosion, 62(2), 146-154.

ICOMOS, 2000. Charter of Krakow. "Principles for conservation and restoration of built heritage.” International conference on conservation, Krakow 2000, Paris.

ISCARSAH, 2003. Recommendations for the analysis, conservation and structural restoration of architectural heritage. International Scientific Committee for Analysis and Restoration of Structures of Architectural Heritage, International Council on Monuments and Sites.

Kalman, H., 2014. Heritage Planning: Principles and Process. Routledge.

Larena, J., Menárquez, A., Lamas, P., Rodríguez, A. \& Jiménez, V., 2011. La consideración patrimonial de las obras públicas. Intervention approaches in the 20th Century architectural heritage: International Conference CAH20thC, Madrid.

Luxán, P., Dorrego, F., Suárez, S., Lorente, R., 1997. Restauración del Mercado do Bolhão do Porto (Portugal): Los materiales existentes y sus técnicas. Instituto de Ciências de la Construccion Eduardo Torroja.

Monteros, F., 2011. Introduction T3. Adition on the 20th Century Architectural Heritage, a Convenient Language. Intervention approaches in the 20th Century architectural heritage: International Conference CAH20thC, Madrid. 
Moreira, F., 2011. Os desafios postos pela conservação da arquitetura moderna. Revista CPC, (11), 152-187.

Zancheti, S., de Figueirôa Silva, A., Braga, A., Gameiro, F., Lira, F. \& Costa, L., 2006. The patina of the city. City \& Time, 2(2), 11-22.

Zancheti, S., 2014. A teoria contemporânea da conservação e arquitetura moderna. Textos para Discussão no ${ }^{\circ}$, Série 2 Gestão de Restauro. Centro de Estudos Avançados da Conservação Integrada. 